\title{
In vitro development of the fish parasite Hysterothylacium aduncum from the third larval stage recovered from a host to the third larval stage hatched from the egg
}

\author{
F. J. Adroher*, D. Malagón, A. Valero, R. Benítez \\ Departamento de Parasitología, Facultad de Farmacia, Campus de Cartuja, Universidad de Granada, 18071 Granada, Spain
}

\begin{abstract}
Anisakids are parasitic nematodes of fish worldwide, producing economic and human health concerns. It is thus important to ascertain their in vitro life cycle in laboratory studies. Here we describe the in vitro development of third-stage larvae (L3) of Hysterothylacium aduncum isolated from blue whiting Micromesistius poutassou, to the hatching of L3 from eggs obtained from $H$. aduncum worms grown in GLIT medium (a modified mixture of Yaeger's LIT [Liver Infusion Tryptose] and Grace's media) at $\mathrm{pH} 4.0,13^{\circ} \mathrm{C}$ and with $5 \% \mathrm{CO}_{2}$ in air. Under these conditions, $\mathrm{L} 3$ recovered from fish developed to mature adults ( 3.4 to $6.2 \mathrm{~cm}$ in length), with oviposition starting from Day 26 in culture. Fertilized eggs (mean size $64 \times 52 \mu \mathrm{m}$ ) had a thick, rugose eggshell and were larger than unfertilized ones (mean size $49 \times 42 \mu \mathrm{m}$ ), whose eggshells were thin and smooth. Eggs laid during the first and second week of oviposition, and maintained in $2.8 \% \mathrm{NaCl}$ solution at $13^{\circ} \mathrm{C}$, developed to L3. Under these maintenance conditions, between 20.6 and $52.5 \%$ of the eggs laid during the first week developed into larvae. Motile larvae, enclosed in a sheath, hatched from between 2 and $11 \%$ of these eggs. The larvae started to hatch $23 \mathrm{~d}$ after deposition. These larvae were 144 to $215 \mu \mathrm{m}$ in length, enclosed in a 237 to $305 \mu \mathrm{m}$-long sheath. This GLIT culture medium may help to study the biology of this and other anisakids.
\end{abstract}

KEY WORDS: Fish parasite $\cdot$ Hysterothylacium aduncum $\cdot$ Nematoda $\cdot$ Anisakidae $\cdot$ In vitro culture $\cdot$ Egg development $\cdot$ Hatching

\section{INTRODUCTION}

Anisakids are parasitic nematodes of fish with a worldwide distribution, some of which can produce economic concern due to their ability to induce mortality in fish larvae (Balbuena et al. 2000, Karlsbakk et al. 2001). They are also responsible for anisakidosis and allergic response in humans (Fernández de Corres et al. 1996, Del Pozo et al. 1997, Fernández-Caldas et al. 1998). In spite of their importance, only few data are available regarding the biology of these parasites. It is thus important to establish the in vitro life cycle in the laboratory to ascertain the different developmental stages of these parasites. This will facilitate morphological identifications, where required, and help to understand the different aspects of their biology and develop effective control measures, especially in cultured fish populations. We are currently working on the in vitro cultivation of anisakids, and we have individually cultured third stage larvae (L3) from fish to adulthood, including some anisakid egg-laying females (Iglesias et al. 2001, 2002). This work consists of some observations on the in vitro development of L3 of Hysterothylacium aduncum from blue whiting Micromesistius poutassou, to the hatching of L3 from eggs obtained by the culture of clustered $H$. aduncum worms.

\section{MATERIALS AND METHODS}

The worms selected for our study were L3 of Hysterothylacium aduncum isolated from the host Micro- 
Fig. 1. Hysterothylacium aduncum egg development stages. (A) Unfertilized egg with smooth, thin eggshell. (B) Fertilized egg; note rugose, thick eggshell with at least 3 layers. (C) Egg in 2-cell stage. (D) Egg in 4-cell stage. (E) Morulae. (F) Larva enclosed in sheath, inside the egg; note the rugose, thick eggshell. (G) Two eggs in tadpole stage among undeveloped eggs with rugose, thick eggshell. (H) Fertilized egg and larvated egg; note eggshell thickness and size of eggs. (I) Larval stage inside highly elongated egg; note smooth, thin eggshell. (J) Free 3rd stage larvae enclosed in the sheath from the 2nd stage larvae; note the oesophagus, and the boring tooth at the cephalic end of the larva. (K) Empty hatched egg; note thickness of eggshell. bt: boring tooth; e: eggshell; l: larva; o: oesophagus; s: sheath; t: tadpole; te: trilamellar eggshell. Scale bars $=50 \mu \mathrm{m}$

mesistius poutassou (blue whiting), family Gadidae, purchased from the fish market of Granada (southern Spain). Blue whiting, on the Atlantic and Mediterranean Spanish coasts, are frequently parasitized by $H$. aduncum (Ruiz-Valero et al. 1992, Valero et al. 2000). The worms, found free in the host body cavity, were collected with the help of a needle with a blunt tip, placed on a Petri dish and washed in $0.9 \% \mathrm{NaCl}$ solution several times. The worms were observed individually under an inverted microscope, and those that showed any kind of internal or external damage were discarded. They were then identified according to morphological features (Hartwich 1975, Petter \& Maillard 1988, Petter \& Cabaret 1995).

Prior to cultivation, each larva was placed in an antibiotic-antifungal solution (80 mg gentamicin sulfate, $0.625 \mathrm{mg}$ amphotericin B, 10000 IU sodium penicillin G, $10 \mathrm{mg}$ streptomycin sulfate and $4.5 \mathrm{ml}$ Hanks' solution, for a final solution volume of $10 \mathrm{ml}$ ) and axenized as described elsewhere (Iglesias et al. 1997, Iglesias et al. 2001). Worms were cultured in sterile polystyrene $30 \mathrm{ml}$ flasks. The culture medium $(10 \mathrm{ml})$ was placed into each flask with 8 to 10 parasites. The culture flasks were then placed in an incubator at $13^{\circ} \mathrm{C}$ and $5 \% \mathrm{CO}_{2}$ in humid air, and the culture medium was renewed once a week. The worms were observed daily for motility, moulting and survival. The culture medium (GLIT) was 1 volume of modified Yaeger's LIT (Liver Infusion Tryptose) medium (Fernandes \& Castellani 1966) and 1 volume of modified Grace's medium (Grace's insect medium added with $2 \% \mathrm{v} / \mathrm{v}$ Basal Medium Eagle vitamins $[100 \times]$ solution + $1 \mathrm{mM}$ L-cysteine $+1 \mathrm{~g} \mathrm{l}^{-1}$ glucose) plus $20 \%(\mathrm{v} / \mathrm{v})$ heat-inactivated foetal bovine serum and $1 \%(\mathrm{w} / \mathrm{v})$ commercial pepsin, at $\mathrm{pH} 4.0,13^{\circ} \mathrm{C}$ and $5 \% \mathrm{CO}_{2}$ in air. The media, sera and reagents were purchased from Sigma Chemical Co. (USA) and Difco Laboratories (USA). Commercial pepsin was obtained from Probus (Spain). This commercial pepsin was analysed by sodium dodecyl sulfate-polyacrylamide gel electrophoresis (SDSPAGE) to determine its purity (Iglesias et al. 2001).

\section{RESULTS AND DISCUSSION}

The L3 of Hysterothylacium aduncum (between 15 and $20 \mathrm{~mm}$ in length), obtained from fish, developed to mature adults (between 3.4 and $6.2 \mathrm{~cm}$ in length). The females laid eggs in the medium, presumably after mating. The development was as follows: the 3rd moult (M3) occurred during Week 1, the 4th moult (M4) occurred during Weeks 2 and 3, and oviposition took place from Day 26 in culture. The eggs were unembryonated when laid. The eggs laid during Weeks 1 and 2 after the onset of oviposition developed to larval stage. The eggs laid in Weeks 3 to 8 of oviposition did not develop. The eggs laid after 3 mo of culture were rounded with thin, smooth walls and scarce content.

The eggs were collected weekly and maintained in $2.8 \% \mathrm{NaCl}$ solution at $13^{\circ} \mathrm{C}$ in $25 \mathrm{~cm}^{2}$ culture flasks with $5 \mathrm{ml}$ of egg suspension. The eggs had negative buoyancy in this saline solution, and tended to be deposited on the bottom of the culture flasks. However, 2 kinds of undeveloped eggs were observed: those showing a thin, smooth external wall (Fig. 1A) and those with a thick, rugose shell (Fig. 1B). Berry \& Cannon (1981) described the fertilized egg from the anisakid Sulcascaris sulcata as a 'thin shell with rugose surface'. We believe the former are unfertilized and/or non-fertilized eggs, while the latter are fertilized (tri-

Table 1. Hysterothylacium aduncum. Size (in $\mu \mathrm{m}$ ) of the eggs obtained in vitro and maintained in $2.8 \% \mathrm{NaCl}$ solution at $13^{\circ} \mathrm{C}(\mathrm{n} \geq 10$ )

\begin{tabular}{|lcrr|}
\hline Egg development & Maximum & Minimum & Mean \\
\hline Non-fertilized ${ }^{\text {a }}$ & - & - & $56.8 \times 47.6$ \\
Undeveloped, thin wall $^{\text {Undeveloped, thick wall }}$ & $65.9 \times 48.8$ & $39.0 \times 37.6$ & $49.2 \times 41.8$ \\
Developing & $75.6 \times 48.8$ & $56.1 \times 46.4$ & $61.4 \times 50.6$ \\
Larval stage & $64.8 \times 60.0$ & $55.2 \times 50.4$ & $61.2 \times 52.4$ \\
a Data from Iglesias et al. (2002) for H. aduncum aduncum & $88.8 \times 48.0 / 76.8 \times 67.2$ & $60.0 \times 51.6 / 55.2 \times 55.2$ & $72.4 \times 54.4$ \\
& & \\
\hline
\end{tabular}



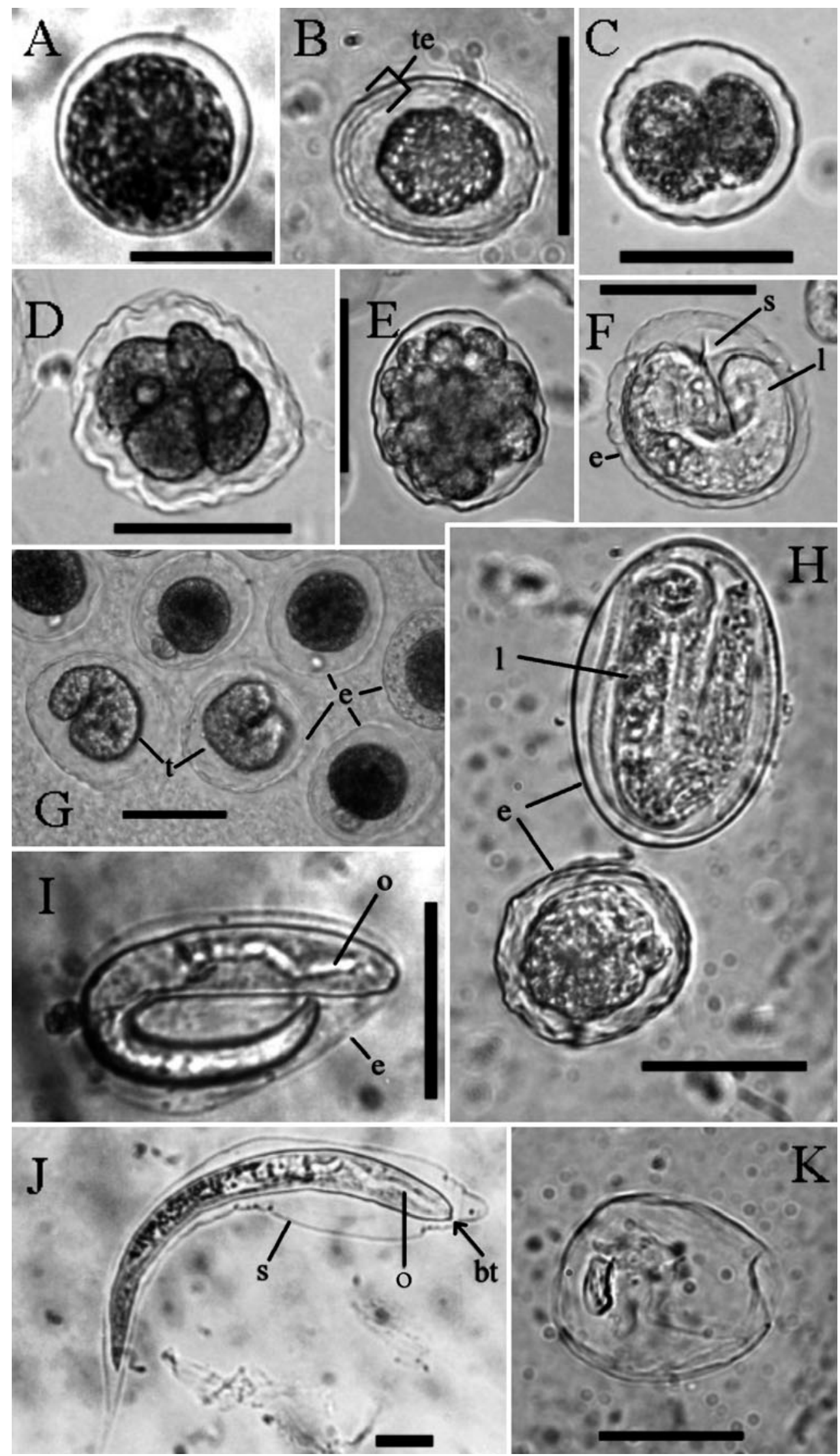
or tetralamellar eggshell, as in other ascaridoids). Generally, the undeveloped eggs with thin walls (Fig. 1A) were less abundant than those with thick walls (Fig. 1C-G). Egg sizes are shown in Table 1. The developing eggs were generally rounded with a thick, multilamellar (see Fig. 1B, eggshell with at least 3 layers) and irregular shell (Fig. 1C-G). The eggs with larvae (Fig. 1H,I) were occasionally highly elongated (e.g. $88.8 \times 48.0 \mu \mathrm{m}$, Fig. $1 \mathrm{I}$ ), perhaps due to proximity to hatching, since both tadpoles (Fig. 1G) and, especially, larvae are motile inside the eggs, and their movements may deform the eggshell. The rugose external layer of the eggs seemed to be lost as hatching occurred (Fig. 1K). Consequently, the observed hatched eggs showed a thinner eggshell than the fertilized eggs (Fig. 1).

Under the above maintenance conditions, between 20.6 and $52.5 \%$ of the eggs laid during Week 1 developed into larval stage. From ca. 2 to $11 \%$ of the eggs, a motile larva hatched enclosed by a sheath (Fig. 1J). Proportions of developing $(<5 \%)$ and hatching $(<1 \%)$ larvae were much lower for the eggs laid in Week 2. For eggs from Week 3 , these percentages were lower than $0.1 \%$. The larvae started to hatch $23 \mathrm{~d}$ after deposition, a time lapse higher than the $10 \mathrm{~d}$ previously reported by Yoshinaga et al. (1987) and Balbuena et al. (1998), although these authors indicated a range of 10 to 22 or 10 to $25 \mathrm{~d}$, respectively. As with the eggs, the hatched larvae also had negative buoyancy in the saline solution used, and tended to be deposited on the bottom of the culture flasks.

There is some controversy regarding the ability of L3 to hatch. While working on parasites from large gadids (Balbuena et al. 1998) and salmonids (González 1998) a general hatching of developed eggs has been reported. However, the research of Køie (1993), working on worms from eelpout (possibly Hysterothylacium auctum), Yoshinaga et al. (1987), working on parasites from freshwater Japanese smelt, which experimentally developed in rainbow trout, and the present study have always shown the rate of hatching larvae to be lower than $33 \%$ in seawater and several saline solutions. Køie (1993), in agreement with Markowski's (1937) observations, concluded that $H$. aduncum from eelpout (probably H. auctum) rarely hatches, and the first intermediate host becomes infected by ingesting the eggs.

There is also a debate about whether L2 (second larval stage) or L3 hatch from the eggs of anisakids. While some authors report that L2 is the stage that hatches (Measures \& Hong 1995), others, however, report L3 to be hatching from anisakid eggs (Berry \& Cannon 1981, Køie 1993, Køie \& Fagerholm 1993, Køie et al. 1995). According to observations by Køie (1993) made on Hysterothylacium aduncum, the hatched larvae were of L3, and were ensheathed in the thick, striated cuticle of L2. This L2 cuticle became widely enlarged as a result of the movements of the larva. In the egg, at least 1 larva turned around inside the cuticle, as was also observed by Køie (1993). Our observations have shown that the larvae measure 144 to $215 \mu \mathrm{m}$ in length, and are surrounded by a 237 to $305 \mu \mathrm{m}$-long sheath ( $\mathrm{n}=$ 10). These values are lower than those reported by other authors (Table 2).

Newly hatched larvae exhibited a flicking motion and generally became readily detached from the empty eggshells. They were also observed flicking in the maintenance solution. Many larvae, when hatched, presented a developed digestive tract, although some did not. They also presented a boring tooth at the cephalic end (Fig. 1J). Hatched, ensheathed larvae lived for over 3 to $4 \mathrm{mo}$ at $13^{\circ} \mathrm{C}$, but without apparent development. Other authors reported larval survival at $5^{\circ} \mathrm{C}$ for over 5 mo (Balbuena et al. 1998), or for $1 \mathrm{wk}$ at $20^{\circ} \mathrm{C}$ (Køie 1993), after hatching and remaining ensheathed.

The differences among some data obtained in this study and those obtained by other authors (Yoshinaga

Table 2. Hysterothylacium aduncum. Characteristics of in vitro hatched larvae. -: not reported

\begin{tabular}{|c|c|c|c|c|c|c|}
\hline Host & Parasite & Region & $\begin{array}{l}\text { Length newly } \\
\text { hatched L3 } \\
(\mu \mathrm{m})\end{array}$ & $\begin{array}{l}\text { Length with } \\
\text { sheath } \\
(\mu \mathrm{m})\end{array}$ & $\begin{array}{c}\text { Fertilized } \\
\text { egg size } \\
(\mu \mathrm{m})\end{array}$ & Source \\
\hline Eelpout Zoarces viviparus & $\begin{array}{l}\text { H. aduncum } \\
(=H . \text { auctum })^{\mathrm{a}}\end{array}$ & Denmark & $270-320$ & - & $50-60$ & Køie (1993) \\
\hline $\begin{array}{l}\text { Gadids (Pollachius virens, } P \text {. pollachius, } \\
\text { Gadus morhua, Molva molva) }\end{array}$ & H. aduncum gadi & Norway & 289 & 386 & - & $\begin{array}{l}\text { Balbuena } \\
\text { et al. (1998) }\end{array}$ \\
\hline Trout Oncorhyncus mykiss & H. aduncum & Chile & $213-235$ & - & $46-50$ & González (1998) \\
\hline Blue whiting Micromesistius poutassou & H. aduncum & Spain & $144-215$ & $237-305$ & $63 \times 52$ & This study \\
\hline
\end{tabular}


et al. 1987, Køie 1993, Balbuena et al. 1998, González 1998) may be due to the occurrence of subspecies of Hysterothylacium aduncum (Hartwich 1975, Petter \& Cabaret 1995). It could also be due to the occurrence of sibling species of $H$. aduncum, suggested by MartínSánchez et al. (1998), as occurs in other anisakids.

Further research into larval hatching and development processes of the genus Hysterothylacium is needed in order to further our knowledge of the complete life cycle events of these parasites.

Acknowledgements. This work has been funded by the Spanish grant ACU01-027 from the INIA. D.M. is recipient of a predoctoral fellowship from Consejería de Agricultura y Pesca, Junta de Andalucía (Spain). Correction of the English was by R. Abrahams.

\section{LITERATURE CITED}

Balbuena JA, Karlsbakk E, Saksvik M, Kvenseth AM, Nylund A (1998) New data on the early development of Hysterothylacium aduncum (Nematoda, Anisakidae). J Parasitol 84:615-617

Balbuena JA, Karlsbakk E, Kvenseth AM, Saksvik M, Nylund A (2000) Growth and emigration of third-stage larvae of Hysterothylacium aduncum (Nematoda: Anisakidae) in larval herring Clupea harengus. J Parasitol 86:1271-1275

Berry GN, Cannon LRG (1981) The life history of Sulcascaris sulcata (Nematoda: Ascaridoidea), a parasite of marine molluscs and turtles. Int J Parasitol 11:43-54

Del Pozo MD, Audícana M, Díez JM, Muñoz D and 6 others (1997) Anisakis simplex, a relevant etiologic factor in acute urticaria. Allergy 52:576-579

Fernandes JF, Castellani O (1966) Growth characteristics and chemical composition of Trypanosoma cruzi. Exp Parasitol 18:195-202

Fernández-Caldas E, Quirce S, Marañón F, Díez-Gómez ML, Gijón-Botella H, López-Román R (1998) Allergenic crossreactivity between third stage larvae of Hysterothylacium aduncum and Anisakis simplex. J Allergy Clin Immunol 101:554-555

Fernández de Corres L, Audícana M, Del Pozo MD, Muñoz D, Fernández E, Navarro JA, García M, Díez J (1996) Anisakis simplex induces not only anisakiasis: report on 28 cases of allergy caused by this nematode. J Invest Allergol Clin Immunol 6:315-319

González L (1998) The life cycle of Hysterothylacium aduncum (Nematoda: Anisakidae) in Chilean marine farms. Aquaculture 162:170-185

Hartwich G (1975) Schlauchwürmer, Nemathelminthes, Rund- oder Fadenwürmer, Nematoda, parasitische Rund-

Editorial responsibility: Wolfgang Körting,

Hannover, Germany würmer von Wirbeltieren. I. Rhabditida und Ascaridida. VEB Gustav Fischer Verlag, Jena

Iglesias L, Valero A, Adroher FJ (1997) Some factors which influence the in vitro maintenance of Anisakis simplex (Nematoda). Folia Parasitol 44:297-301

Iglesias L, Valero A, Benítez R, Adroher FJ (2001) In vitro cultivation of Anisakis simplex: pepsin increases survival and moulting from fourth larval to adult stage. Parasitology 123:285-291

Iglesias L, Valero A, Gálvez L, Benítez R, Adroher FJ (2002) In vitro cultivation of Hysterothylacium aduncum (Nematoda: Anisakidae) from 3rd-stage larvae to egg-laying adults. Parasitology 125:467-475

Karlsbakk E, Otterlei E, Høie H, Nylund A (2001) Parasites of cultured cod (Gadus morhua) postlarvae fed natural zooplankton. Bull Eur Assoc Fish Pathol 21:63-70

Køie M (1993) Aspects of the life cycle and morphology of Hysterothylacium aduncum (Rudolphi, 1802) (Nematoda, Ascaridoidea, Anisakidae). Can J Zool 71:1289-1296

Køie M, Fagerholm HP (1993) Third-stage larvae emerge from eggs of Contracaecum osculatum (Nematoda, Anisakidae). J Parasitol 79:777-780

Køie M, Berland B, Burt MDB (1995) Development to thirdstage larvae occurs in the eggs of Anisakis simplex and Pseudoterranova decipiens (Nematoda, Ascaridoidea, Anisakidae). Can J Fish Aquat Sci 52:134-139

Markowski S (1937) Über dir Entwicklungsgeschichte und Biologie des Nematoden Contracaecum aduncum (Rudolphi 1802). Bull Acad Pol Sci Lett B 2:227-247

Martín-Sánchez J, Paniagua I, Valero A (1998) Contribution to the knowledge of Hysterothylacium aduncum through electrophoresis of the enzymes glucose phosphate isomerase and phosphoglucomutase. Parasitol Res 84:160-163

Measures LN, Hong H (1995) The number of moults in the egg of sealworm, Pseudoterranova decipiens (Nematoda: Ascaridoidea): an ultrastructural study. Can J Fish Aquat Sci 52:156-160

Petter AJ, Cabaret J (1995) Ascaridoid nematodes of teleostean fishes from the eastern North Atlantic and seas of the north of Europe. Parasite 2:217-230

Petter AJ, Maillard C (1988) Larves d'ascarides parasites de poissons en Méditerranée occidentale. Bull Mus Natl Hist Nat Paris, 4e Sèr, A, Zool Biol Ecol Anim 10:347-369

Ruiz-Valero J, Valero A, Adroher FJ, Ortega JE (1992) Presencia de ascáridos en peces comerciales de frecuente consumo en Granada. In: Hernández S (ed) In memoriam al Profesor Doctor D.F. de P. Martínez Gómez. Universidad de Córdoba, Córdoba, p 335-349

Valero A, Martín-Sánchez J, Reyes-Muelas E, Adroher FJ (2000) Larval anisakids parasitizing the blue whiting (Micromesistius poutassou) captured from Motril bay in the Mediterranean region of southern Spain. J Helminthol 74:361-364

Yoshinaga T, Ogawa K, Wakabayashi H (1987) Experimental life cycle of Hysterothylacium aduncum (Nematoda: Anisakidae) in fresh water. Fish Pathol 22:243-251

Submitted: July 8, 2003; Accepted: September 22, 2003

Proofs received from author(s): December 19, 2003 